Наносистели, нанолатеріали, нанотехнології Nanosistemi, Nanomateriali, Nanotehnologii 2020 , т. 18, № 3, сc. 663-668 (c) 2020 ІМФ (Інститут металофізики ім. Г. В. Курдюмова НАН України) Надруковано в Україні. Фотокопіювання дозволено тільки відповідно до ліцензії

PACS numbers: 71.35.Ee, 73.20.Mf, 73.21.La

\title{
Spatially Indirect Excitons' Spectroscopy in Germanium Quantum Dots
}

\author{
S. I. Pokutnyi
}

O. O. Chuiko Institute of Surface Chemistry, N.A.S. of Ukraine, 17, General Naumov Str., UA-03164 Kyiv, Ukraine

As shown, taking into account the centrifugal energy in the Hamiltonian of an exciton with spatially separated electron and hole (the hole moves in the germanium quantum dot, and the electron is localized over the spherical interface of the silicon matrix-quantum dot) leads to the appearance of quasistationary states in the zone of surface exciton states, which transform into stationary states with increasing quantum dot radius. As determined, the absorption spectra of the nanosystem interband consist of energy bands, which are formed by electron transitions between quasi-stationary and stationary states, and the intraband absorption spectra consist of zones formed by electron transitions between stationary states.

Показано, що врахування відцентрової енергії в Гамільтоніяні екситона 3 просторово розділеними електроном і діркою (дірка рухається у квантовій точці германію, а електрон локалізується над сферичною поверхнею поділу квантова точка-матриця кремнію) приводить до появи квазистаціонарних станів у зоні поверхневих екситонних станів, які з ростом радіюса квантової точки переходять у стаціонарні стани. Встановлено, що спектри міжзонного поглинання наносистеми складаються з енергетичних зон, утворених електронними переходами між квазистаціонарними та стаціонарними станами, а спектри внутрішньозонного поглинання складаються із зон, які формуються електронними переходами між стаціонарними станами.

Key words: indirect excitons, quasi-stationary states, quantum dots.

Ключові слова: непрямі екситони, квазистаціонарні стани, квантові точки.

(Received 10 December, 2019) 


\section{INTRODUCTION}

$\mathrm{Ge} / \mathrm{Si}$ heterostructures with germanium quantum dots (QDs) are of the second type of heterostructures. Inside them, the main electron level is located in the silicon matrix, and the main hole level is in the germanium QD. When studying the optical properties of Ge/Si nanosystems with germanium QDs, experimental work [1] was the first to reveal the spatial separation of electrons and holes, as a result of which electrons were localized above the QD surface, and holes moved into QDs. The transition between such states was indirect in space. In experimental studies [1,2], it was established that, in nanosystems consisting of germanium QDs located in silicon matrices, the excitation of spatially indirect excitons (SIE) is possible.

In Ref. [3], heterostructures, which are linear germanium QD chains on silicon substrates, were obtained using the method of electron beam lithography. The average radii of QD of germanium did not exceed 30 $\mathrm{nm}$. In $\mathrm{Ge} / \mathrm{Si}$ heterostructures with germanium QDs, it was established in experimental works $[1,2]$ that low-temperature optical absorption and photoluminescence spectra were caused by interband electron transitions from the valence band of germanium QD to the conduction band of the silicon matrix. The photoluminescence signal of nanostructures in the infrared spectral region $0.20-1.14 \mathrm{eV}$ was observed up to room temperature [1, 2].

The theory predicts that exciton containing a hole in QD volume and electron localized above outer spherical interface (QD-silicon matrix), has the binding energy two orders of magnitude higher than exciton in appropriate bulk semiconductors $[4,5]$. Electron and the hole are separated by centrifugal potential, as well as polarization interaction with curved interface (QD-silicon matrix) [5]. The energy spectrum of this exciton depends on QD size [5]. Due to low electron and hole wave function overlap, an SIE shows the long lifetime [1, 2].

\section{THEORETICAL DETAILS}

\subsection{The Energy Spectrum of a Spatially Indirect Exciton in a Nanosystem}

Quantitative estimation of the QD size corresponding to various exciton states can be carried out using the real nanosystem [1-3] containing the germanium QD with a radius $a$ and permittivity $\varepsilon_{2}=16.3$, in silicon matrix with $\varepsilon_{1}=11.7$. In this nanosystem, a hole with effective mass $\left(m_{h} / m_{0}\right)=0.39$ moves in QD volume, and electron with effective mass $\left(m_{e} / m_{0}\right)=0.98$ moves in silicon matrix $\left(m_{0}\right.$ is free electron mass), $r_{e}$ and $r_{h}$ are electron and hole distances from the QD centre [4, 5]. In nanosystem, the main electronic level is located in silicon ma- 
trix, and the main hole level is in the QD. The energy of electron-hole Coulomb interaction and energy polarization interaction causes localization of the electron in a potential well above the surface of the QD [48]. For simplicity, we assume that a hole $h$ with effective mass $m_{h}$ is located at the QD centre (with $r_{h}=0$ ), and an electron $e$ with effective mass $m_{e}$ is localized over the spherical surface of the QD in the silicon matrix ( $r_{e}=r$ is distance of the electron $e$ from the $\mathrm{QD}$ centre).

In the model of quasi-zero-dimensional nanosystem within the framework of the effective-mass approximation, the Hamiltonian of the SIE takes the form [6]:

$$
H(r, a)=-\frac{\hbar^{2}}{2 \mu_{e x}} \frac{1}{r^{2}} \frac{d}{d r}\left(r^{2} \frac{d}{d r}\right)+\frac{\hbar^{2} l(l+1)}{2 \mu_{e x} r^{2}}-\frac{e^{2}}{\tilde{\varepsilon} r}-\frac{e^{2} \beta a^{3}}{\varepsilon_{1} r^{2}\left(r^{2}-a^{2}\right)}+\frac{e^{2} \beta}{\varepsilon_{2} a}+E_{g},
$$

where the first term is the kinetic energy operator of the SIE, $\mu_{e x}=m_{e} m_{h} /\left(m_{e}+m_{h}\right)$ - reduced mass of the SIE, the second term describes the centrifugal energy of the SIE (where $L^{2}=l(l+1), l=0,1,2$, ...- orbital quantum number of an electron), the third term describes the energy of electron-hole Coulomb interaction, the fourth and fifth terms describes the energy of the polarization interaction of an electron and a hole with a QD surface, $\tilde{\varepsilon}=2 \varepsilon_{1} \varepsilon_{2} /\left(\varepsilon_{1}+\varepsilon_{2}\right)$ is the permittivity of the nanosystem, $\beta=\left(\varepsilon_{2}-\varepsilon_{1}\right) /\left(\varepsilon_{1}+\varepsilon_{2}\right)$ is the nanosystem parameter, $E_{a}$ is the bandgap energy of the silicon matrix.

To estimate the energy spectrum of the ground state of an exciton $(n=1, l)$, a variational method was used. The average value of the Hamiltonian (1) SIE on hydrogen-like wave functions is obtained in [6]:

$$
E_{1, l}\left(a, j_{l}(a)\right)=\left\langle R_{1, l}(r)|H(r, a)| R_{1, l}(r)\right\rangle,
$$

where

$$
\begin{gathered}
R_{1, l}(r)=A_{l}(r-a)^{l} \exp \left(-j_{l}(r-a) / a\right), \\
A_{1, l}^{2}=\left(2 j_{l} / a\right)^{3+2 l}\left(4(2 l) ! j_{l}^{2}+4(2 l+1) ! j_{l}+(2 l+2) !\right)^{-1},
\end{gathered}
$$

are the hydrogen-like radial wave functions, $j_{l}(a)$ is variational parameter. From the results of a variational calculation of the energy y $E_{1, l}(a)$ (2) of the ground state of the SIE, it follows that, in contrast to excitons in a bulk material when radius of QD $a$ increased, starting from the size

$$
a_{C}^{*}(1, l) \leq a \leq a_{C}(1, l),
$$

the band of exciton quasi-stationary states appears above the bottom of 
the conduction band of the silicon matrix. With a further increase of QD radius,

$$
a>a_{C}(1, l)>a_{C}^{*}(1, l),
$$

the quasi-stationary states become the stationary states in the band gap of the silicon matrix [6]. The critical QD radii for these states $(n=1, l \leq 3)$ have corresponding values [6]: $a_{C}(1, l)=8.04 \mathrm{~nm} ; 11.1 \mathrm{~nm}$; $15.5 \mathrm{~nm} ; a_{C}(1, l)=6.54 \mathrm{~nm} ; 8.35 \mathrm{~nm} ; 11.95 \mathrm{~nm} ; 17.34 \mathrm{~nm}$.

The results shown that upper boundary of the quasi-stationary states band $E_{1, l}^{\max }(a)$ takes the maximum value for $(n=1, l=3)$, and $E_{1, l=3}^{\max }\left(a=a_{C}^{*}(1, l=3)\right) \cong 248.4 \mathrm{meV}$. In the interval

$$
a \geq \tilde{a}_{C}(1, l)=20.8 \mathrm{~nm},
$$

exciton stationary states $E_{1, l}(a)(2)$ approach to the states of $2 D$ SIE localized close to flat interface (germanium-silicon) [6]. The energy of this exciton [6-8] is equal to:

$$
E_{1, l}(a)=-E_{e x}^{2 D}, E_{e x}^{2 D}=2 \hbar / \mu_{e x}\left(a_{e x}^{2 D}\right)^{2},
$$

where $E_{e x}^{2 D}=82 \mathrm{meV}$ is the binding energy of $2 D$ SIE. The $2 D$ SIE Bohr radius is defined as

$$
a_{e x}^{2 D}=\tilde{\varepsilon}\left(m_{0} / \mu_{e x}\right)\left(\hbar^{2} / m_{0} e^{2}\right),
$$

where $a_{e x}^{2 D}=2.6 \mathrm{~nm}$.

Thus, the ground state $(n=1)$ of SIE energy spectrum $E_{1, l}^{\max }(a)$ is formed by stationary states band with $\Delta E=E_{e x}^{2 D}=\hbar \omega_{e x}^{2 D}=82 \mathrm{meV}$ width and quasi-stationary states band with $\Delta E=E^{\max }=248.4 \mathrm{meV}$ width. It means that SIE energy spectrum is limited by $-82 \mathrm{meV}$ and $248.4 \mathrm{meV}$ relatively to silicon matrix conduction band bottom. It clearly depends on the size of the QD and contains a finite number of exciton states $(n=1, l=0,1,2,3)$ that contribute to the formation of the nanosystem light absorption spectrum discussed in [6].

\section{RESULTS AND DISCUSSION}

Using the present model of a $\mathrm{Ge} / \mathrm{Si}$ heterostructure with germanium QDs, it was shown [5] that interband and interband transitions between SIE states caused significant radiation in the infrared region of wavelengths in the energy range $(\leq 330 \mathrm{meV})$. This energy range $(\leq 330$ $\mathrm{meV}$ ) was contained in the spectral region $0.20-1.14 \mathrm{eV}$, which was observed in experiments [1-3]. Therefore, the present model of the $\mathrm{Ge} / \mathrm{Si}$ heterostructure with germanium QDs partially explains the experi- 
mental results [1-3].

It should be noted that SIE lifetime depends on the tunnelling rate of an electron and a hole through the potential barrier of QD-medium interface, and it can be expected that, varying the parameters of nanosystem materials, the SIE lifetime also changes.

The nature of the appearance of the zone of surface states of the exciton is described in a nanosystem containing germanium QD grown in the silicon matrix [5-8]. It is found that, with growth of the QD radius starting from the value of a greater than some critical radius of the quantum dot $a_{C}^{*}(1, l)$, quasi-stationary states first appear, which are converted into stationary states with increasing QD radius $a(5)$.

\section{CONCLUSION}

Quasi-stationary and stationary states form a zone of surface states of the exciton. Stationary states of the exciton in the nanosystem are located in the bandgap of the silicon matrix $[5,6]$. They are bounded below by the level, which characterizes the ground state binding energy of a two-dimensional exciton. Quasi-stationary states of the exciton are located in the conduction band of the silicon matrix [6]. They are bounded from above by the boundary of the spectrum $E_{1, l}^{\max }(a)$ Mechanisms underlying the formation of the interband and intraband absorption (emission) spectra in a nanosystem are proposed. It is shown that spectra of interband absorption (emission) consist of energy bands that are formed by electron transitions between quasi-stationary and stationary states, and intraband absorption spectra consist of zones that appear due to electron transitions between stationary states [5-10].

\section{REFERENCES}

1. A. I. Yakimov, A. V. Dvurechensky, and A. I. Nikiforov, JETP Lett., 73, No. 10: 529 (2001); https://doi.org/10.1063/1.5049165.

2. A. I. Yakimov, A. V. Dvurechensky, and N. P. Stepina, JETP, 92, No. 3: 500 (2001); https://doi.org/10.1134/1.1364747.

3. J. V. Smagina, A. V. Dvurechensky, and V. A. Seleznev, Semiconductors, 49, No. 6: 749 (2015); https://doi.org/10.1134/S1063782615060238.

4. S. I. Pokutnyi, Semiconductors, 41, No. 11: 1323 (2007); https://doi.org/10.1134//S1063782607110097.

5. $\quad$ S. I. Pokutnyi, Low Temp. Phys., 42, No. 12: 1151 (2016); https://doi.org/10.1063/1.4973506.

6. S. I. Pokutnyi, Low Temp. Phys., 44, No. 8: 819 (2018); https://doi.org/10.1063/1.5049165.

7. S. I. Pokutnyi, Semiconductors, 47, No. 6: 791 (2013); https://doi.org/10.1134/S1063782613060225.

8. $\quad$ S. I. Pokutnyi, Technical Physics Letters, 39, No. 3: 233 (2013); 
https://doi.org/10.1134/S1063785013030139.

9. V. P. Dzyuba, S. I. Pokutnyi, and Y. N. Kulchin, J. Phys. Chem. C, 123, No. 42: 26031 (2019); https://doi.org/10.1021/acs.jpcc.9b08892.

10. S. I. Pokutnyi, Semiconductors, 53, No. 16: 1 (2019); https://doi.org/10.1134/S1063782619120212. 